\title{
Editorial
}

\section{Gestational Trophoblastic Disease in Brazil}

\author{
Antonio Braga ${ }^{1}$ Lawrence Hsu Lin ${ }^{2}$ Izildinha Maestá ${ }^{3}$ Sue Yazaki Sun ${ }^{4}$ Elza Uberti ${ }^{5}$ \\ José Mauro Madi ${ }^{6}$ Maurício Viggiano ${ }^{7}$ \\ ${ }^{1}$ Department of Obstetrics and Gynecology, Universidade Federal do \\ Rio de Janeiro, Rio de Janeiro, RJ, Brazil \\ 2 Department of Obstetrics and Gynecology, Universidade de São \\ Paulo, São Paulo, SP, Brazil \\ ${ }^{3}$ Department of Obstetrics and Gynecology, Universidade Estadual \\ Paulista, Botucatu, SP, Brazil \\ ${ }^{4}$ Department of Obstetrics, Paulista Medical School, Universidade \\ Federal de São Paulo, São Paulo, SP, Brazil \\ ${ }^{5}$ Maternity Mario Totta, Santa Casa de Misericórdia, Porto Alegre, RS, \\ Brazil \\ ${ }^{6}$ Center for Life Science, Universidade de Caxias do Sul, Caxias do Sul, \\ RS, Brazil \\ 7 Department of Obstetrics and Gynecology, Universidade Federal de \\ Goiás, Goiânia, GO, Brazil
}

Rev Bras Ginecol Obstet 2019;41:211-212.

Gestational trophoblastic disease (GTD) is a group of conditions characterized by abnormal proliferation of placental trophoblast. Hydatidiform mole (HM) is the most common form of GTD, which has a frequency of 1 case per 1,000 pregnancies in North America and Europe; however, the incidence of the disease is thought to be at least two to three times higher in Brazil. ${ }^{1,2}$

In developing countries, due to the delay in diagnosis of $\mathrm{HM}$, it is not uncommon for patients to develop clinical complications, which can represent causes of potentially life-threatening conditions, maternal near miss and maternal deaths. ${ }^{3}$ The only way to prevent those adverse outcomes is the early diagnosis of HM and prompt uterine evacuation. After uterine evacuation, patients with HM need to be carefully followed due to the risk of development of gestational trophoblastic neoplasia (GTN). The early diagnosis of GTN is key to ensure cure, and patients with late diagnosis of GTN require more aggressive and toxic treatment and hold worse prognosis, often with metastatic disease. ${ }^{1}$ Official national data on the morbidity and mortality rates of patients with GTD is not available. Currently, a nationwide collaborative study is in progress to better understand the morbidity and mortality of patients with GTN in Brazil, through the Brazilian Network for Gestational Trophoblastic Disease Study Group, which has developed several collabo-

(1) Antonio Braga's ORCID is https://orcid.org/0000-0002-29426182.

Address for correspondence Antonio Braga, MD, PhD, Rua das Laranjeiras, 180, 22240-000, Laranjeiras, Rio de Janeiro, RJ, Brazil (e-mail: antonio.

braga@ufrj.br). rative studies over the last years to advance the understanding of GTD. ${ }^{4,5}$

The Comissão Nacional Especializada em DTG (Special National Committee on GTD), an initiative of the Federation of Brazilian Associations of Gynecology and Obstetrics (FEBRASGO), has been focusing on continued medical education through free online management protocols and several national and regional teaching events with the Nation's leading specialists.

The importance of reference centers in the management of patients with GTD has been highlighted in various studies, showing that patients present better outcomes when they are initially followed at those centers. ${ }^{6}$ The GTD reference centers are able to follow and manage patients within the full spectrum of GTD with a multidisciplinary team and a personalized approach. The Associação Brasileira de Doença Trofoblástica Gestacional (Brazilian Association of Gestational Trophoblastic Disease), over the last years, had the task to help to establish GTD reference centers across the Nation. Currently, there are 47 centers in Brazil and at least one in each of the Brazilian states, shortening the distance between the patients and the treatment of excellence through the public health system. ${ }^{7}$

The official government referral system that refers patients in primary care to secondary and tertiary care is one way for patients to reach a GTD reference center. However, this referral system is far from being perfect, as many patients are referred late, sometimes with severe complications. Therefore, making technology and social media allies, the Associação Brasileira de Doença Trofoblástica

Copyright $\odot 2019$ by Thieme Revinter Publicações Ltda, Rio de Janeiro, Brazil
DOI https://doi.org/ 10.1055/s-0039-1688566. ISSN 0100-7203.
License terms

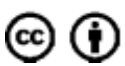


Gestacional created a Facebook page (currently with over 7,700 members, including patients, relatives and healthcare providers) that helps patients reach the nearest reference center, find reliable information of the disease online, and also serve as a patient support group. ${ }^{8,9}$

Gestational trophoblastic disease is a complex group of diseases. Their early diagnosis and treatment are fundamental to achieve cure. ${ }^{10}$ Brazil, being a country of continental dimensions, makes the task of treating patients with such rare diseases very difficult. Therefore, several initiatives by Associação Brasileira de Doença Trofoblástica Gestacional and Comissão Nacional Especializada em DTG are in action and being implemented to foster the better care of patients with GTD across the Nation.

Conflicts to Interest

The patients declare that there were no conflicts of interest.

\section{References}

1 Maestá I, Braga A. [Challenges of the treatment of patients with gestational trophoblastic disease]. Rev Bras Ginecol Obstet 2012; 34(04):143-146 10.1590/S0100-72032012000400001

2 Braga A, Uberti EMH, Fajardo MdoC, et al. Epidemiological report on the treatment of patients with gestational trophoblastic disease in 10 Brazilian referral centers: results after 12 years since International FIGO 2000 Consensus. J Reprod Med 2014;59(5-6): 241-247
3 Sun SY, Goldstein DP, Bernstein MR, et al. Maternal near miss according to world health organization classification among women with a hydatidiform mole: experience at The New England Trophoblastic Disease Center, 1994-2013. J Reprod Med 2016;61(5-6):210-214

4 Braga A, Souza PO, Esteves APVS, et al. Brazilian network for gestational trophoblastic disease study group consensus on management of gestational trophoblastic disease. J Reprod Med 2018;63:261-270

5 Braga A, Burlá M, Freitas F, et al; Brazilian Network for Gestational Trophoblastic Disease Study Group. Centralized coordination of decentralized assistance for patients with gestational trophoblastic disease in Brazil: a viable strategy for developing countries. J Reprod Med 2016;61(5-6):224-229

6 Dantas PRS, Maestá I, Cortés-Charry R, et al. Influence of hydatidiform mole follow-up setting on postmolar gestational trophoblastic neoplasia outcomes: a cohort study. J Reprod Med 2012;57 (7-8):305-309

7 Brazilian Federation of Gynecology and Obstetrics Associations. [Where should a patient with hydatidiform mole be treated?]. 2017https://www.febrasgo.org.br/pt/noticias/item/206-onde-apaciente-com-mola-deve-ser-tratada. Accessed April 3, 2019.

8 Victoria Diniz M, Sun SY, Barsottini C, et al. Experience with the use of an online community on Facebook for Brazilian patients with gestational trophoblastic disease : netnography study. J Med Internet Res 2018;20(09):e10897 10.2196/10897

9 Brazilian Association of Gestational Trophoblastic Disease. Facebook Page. https://www.facebook.com/groups/443530852424434. Accessed April 3, 2019.

10 Braga A, Mora P, de Melo AC, et al. Challenges in the diagnosis and treatment of gestational trophoblastic neoplasia worldwide. World J Clin Oncol 2019;10(02):28-37 10.5306/wjco.v10.i2.28 